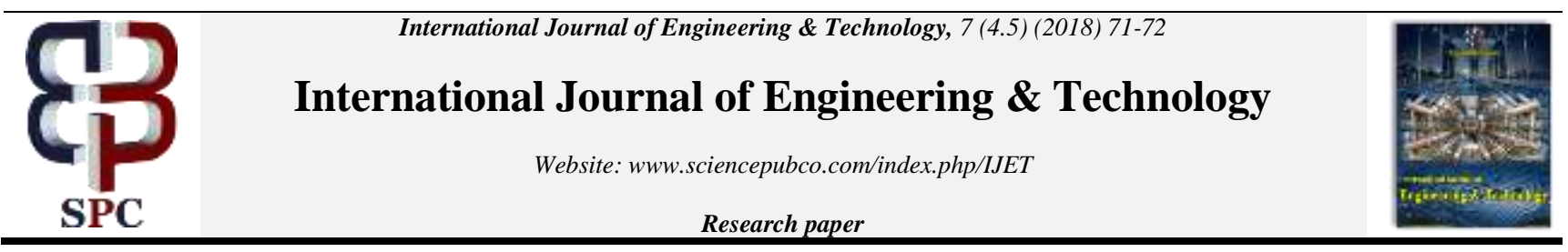

\title{
The Significance of Vedic Science for Artificially Intelligent Systems
}

\author{
Anshuman $^{1}$, Upendra Kumar ${ }^{2}$ \\ 1Research Scholar, \\ Dept. of Computer Science \& Engineering \\ BIT Mesra, Patna Campus, \\ Patna, Bihar, India \\ 2Asst. Professor \\ Dept. of Computer Science \& Engineering \\ BIT, Mesra, Patna Campus, \\ Patna, Bihar, India \\ *Email: anshuman.aryaa@gmail.com
}

\begin{abstract}
The significance of Vedic Sciences is well proven. Vedic concepts are suitable as well as necessary for an efficient lead in the field of Artificial Intelligence (AI). The concept is very crisp: To lace the man-made machines with the ideology described in the Vedic scriptures, to build a better and smarter society. Well proven concepts to build better machines.
\end{abstract}

Keywords: Artificial Intelligence; Expert Systems; Natural Language Processing; Sanskrit; Vedic Science; Vedic Knowledge.

\section{Introduction}

\section{"The value based expert systems: boon for society"}

The transfer of knowledge to the so called zero IQ machine is a very tedious and risky task. Similarly, while designing a machine capable of taking decisions on its own is much more complex. The main idea is to implement the ancient Vedic knowledge that was used to teach the human race. Well proven and vastly appreciated Vedic text and value based learning from scriptures is a source of all kind of data, information and knowledge for rationalization of the basis for taking a decision. Such knowledge can be stored to create expert systems, capable of using the Vedic knowledge. Being able to design such a system can be of great importance, as the machines would be behaving ideally. Thus Vedic knowledge is much significant as the basic data, to be used by the expert systems while decision making process.

Corruption being the most disturbing element in today's society can be removed by using machines that are able to perform decision making on the basis of Vedic knowledge. As machines might also get corrupted, at some point of time, other machines can be used to sort out the problems, again as per value-based knowledge from the Vedic scriptures.

Some of the advantages for implementing Vedic knowledge with AI based systems are as follows - :

- $\quad$ Reflects need of modern society

- Improves sustainability

- Improves autonomy

- Improves understanding
- Better reliability

- Better performance

However, it is to be understood that all of the above advantages concerned to the implementation of the Vedic knowledge are dependent on the criteria of application and can get complex, if not taken proper care, such as -:
* Increased complexity
* Costlier implementation initially
* Lack of experience personnel

Therefore, the implementation of AI based tools and techniques, is a good way out, by which the AI systems can work more efficiently.

\section{Methodology}

There can be several fields for implementations; however we can focus initially on the following -

\subsection{Sanskrit: Naturally Built for Machines}

The Sanskrit being the most ancient language (from explanation of evolution of universe - Bhagvad Gita), is also well structured and compilers needed to be designed for the same. That will help in implementing the Vedic knowledge in the most accurate and efficient manner.

The proposed work is to make an artificial intelligent system (machine or program or both) that is combined with the knowledge of Vedic sciences. For this we are planning to extract the information 
from the different branches of Vedic sciences and feed the machine to use them.

How a machine may understand human beings more effectively and work for the benefit of the human race, can't be explored better than the ancient Vedic scriptures, which are assumed to be followed by the oldest and most sophisticated civilizations in the world.

The states and behaviour of the artificially intelligent system proposed is to be based on the information from Vedic literatures and uses this information for deciding next step or process to be taken by the system. Analysis of the outside nature and other living and non-living things is one of the major tasks to be taken under consideration by this artificial intelligent system. A system that would be closer to the thinking process of a human is needed to take care of several aspects of human life.

Our process of implementation goes as follows:-

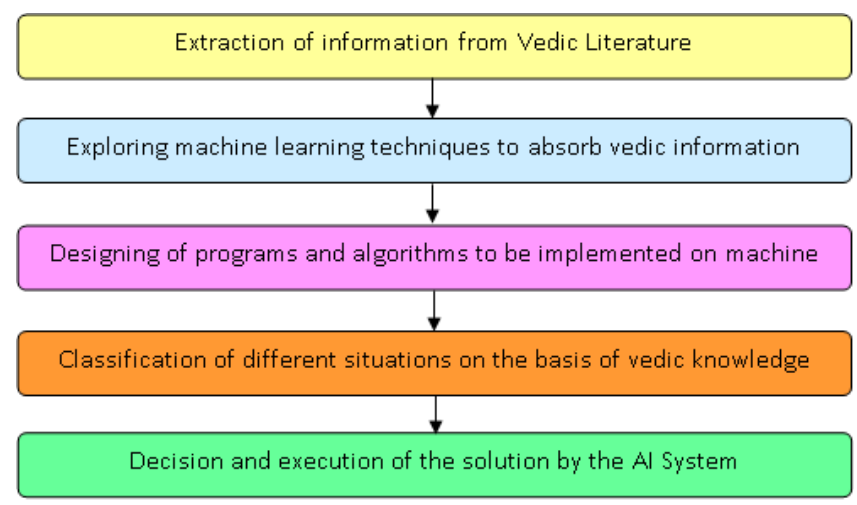

Fig. 1: Flowchart of the implementation process

\subsection{Building Atoms: Converting Aphorism to Neurons}

The real task to be accomplished can be understood as the most complex one, to generate neurons for the overall system to work upon. The knowledge representation and observance can be further broken down from the Sanskrit aphorisms to the tiny bits that can be compiled into binary code through the appropriate compilers. The neural network working in the machine can rely upon the data available from the Vedic scriptures in forms of the neurons. Using natural language processing and genetic algorithms, we can design a basic system that includes working parts that can understand Sanskrit like language and may work upon more complex systems.

\subsection{Better Decision Making: Implementing Vedic Knowledge}

Systems based on such knowledge will be able to make better decisions and will be able to rationalize situations in an ethical manner.

\section{Conclusion}

A concept for well versed series of systems is devised to serve the society. AI may explore new paths into the universe, just like NASA planning to echo Sanskrit into space. Thus we conclude that, Vedic knowledge is very much significant to the field of AI.

\section{Acknowledgement}

I would like to thank, the almighty. To my parents, my mentors, institute guides and my dynamic students who keep putting their doubts, so that I keep myself ever searching for different types of information.

\section{References}

[1] Shri Durga SaptShati, Gitapress, Gorakhpur \#19-29 Devyah Kavacham

[2] Vedic Mathematics, Swami Sri Bharti Krishna Tirth ji Maharaj, Motilal Banarasi Das Publishers

[3] Rick Briggs. Knowledge Representation in Sanskrit and Artificial Intelligence, The AI Magazine, RIACS, NASA Ames Research Centre

[4] Nilsson, Nils J. Principles of Artificial Intelligence. Palo Alto: Tioga Publishing Co.

[5] Russel, Norvig. Artificial Intelligence : A Modern Approach, Pearson Prentice Hall

[6] Kosko, Bart. Neural Networks and Fuzzy Systems, Prentice Hall India

[7] Rich, Knight, Nair. Artificial Intelligence, Mc Graw Hill.

[8] Patterson, Dan W. Introduction to Artificial Intelligence and Expert Systems, Prentice Hall India

[9] Bhatta, Nagesha (1963) Vaiyakarana-Siddhanta-Laghu-Manjusa, Benares Chowkhamba Sanskrit Series Office.

[10] Sanskrit Effects : James Hartzell [2018] 